\title{
Burning Characteristics of Aluminized Solid Rocket Propellants with Bimodal Oxidizer Size Distribution
}

\author{
Bachar Elzein $^{1}$, Jacques Xing ${ }^{1}$, Étienne Robert ${ }^{1}$, Nicholas Montoya ${ }^{2}$ \\ ${ }^{1}$ École Polytechnique de Montreal \\ 2900 boul. Édouard-Montpetit \\ Montréal, Canada \\ Bachar-2.elzein@Polymtl.ca; Jacques-2.xing@polymtl.ca; Etienne.robert@polymtl.ca \\ ${ }^{2}$ University of California, San Diego \\ 500 Gilman Dr, La Jolla \\ CA, United States \\ Nicomontoya09@gmail.com
}

\section{Extended Abstract}

The operations and design of solid rocket motors depend heavily of the combustion characteristics of the propellant, mainly the burning rate, the evolution of the burning surface and the propellant's initial geometry. A critical step for the accurate modeling of motor performance is propellant characterization, starting with the determination of its burn rate coefficient [a] and pressure exponent [n] to be used in Vielle's Law. These parameters however need to be precisely measured experimentally as no reliable theoretical framework exist to provide predictions based only on chemical composition.

This paper investigates the effects of a bimodal ammonium perchlorate (AP) size distribution on the burn rate characteristics of an aluminized composite propellant using Polybutadiene Acrylonitrile Acrylic Acid (PBAN) as a binder. The mass ratio of the coarse to fine AP (AP c/f) is the primary variable under investigation and 4 propellants compositions are considered.

Because of safety and cost considerations during testing, rocket motors at reduced sizes have been used here to evaluate propellants; such small motors can be fitted with nozzles of different sizes to provide the desired operating pressures. However, the burn rate of a propellant is also known to depend on other variables besides pressure, notably the propellant's chemical formulation and the microstructure of the reactants. Propellant formulations incorporating aluminum as a fuel have been the subject of an extensive literature, for a review see the work of Davenas [1].

A major problem in the combustion of solid rocket propellants is the agglomeration of metal particles, as it impairs energy conversion and can result in a two-phase aerosol flow that reduces specific impulse by 4-6\% [2]. Since the combustion efficiency of a solid rocket motor is tributary to its ability to achieve complete combustion of the metal particles contained in the fuel within the motor cavity, a strong correlation exists between the metal agglomerate size, the oxidizer microstructure and the propellant burning rate [3]. Ammonium perchlorate (AP) is the most widely used crystalline oxidizer in solid propellants, because of its good compatibility with various fuels, desirable burning characteristics and availability [4].

The present study was motivated by the need to identify the optimal AP c/f ratio for a solid rocket propellant, using components that are accessible and affordable, to minimize the agglomeration of metal particles. A series of 12 hot fire tests were conducted to establish a correlation between the AP c/f mass fraction and the propellants burning rate, combustion pressure and combustion efficiency. Formulations with low AP c/f ratio had a tendency to burn faster and at higher pressures. Additionally, the measured experimental characteristic velocity $\mathrm{C}^{*}$ of low AP c/f formulations was shown to be closer to the theoretically predicted values compared to analogs with higher AP c/f mass fraction. This variation in performance is likely associated with smaller average oxidizer particle size, increasing reactive surface area, hence increasing combustion efficiency. 


\section{References}

[1] A. Davenas, "Development of Modern Solid Propellant," Journal of Propulsion and Power, vol. 19, No. 6, pp. 1108$1128,2003$.

[2] A. Bandera, F. Maggi, L. T. DeLuca, "Agglomeration of Aluminized Solid Rocket Propellants," in 45th AIAA/ASME/SAE/ASEE Joint Propulsion Conference \& Exhibit, Joint Propulsion Conferences, Denver, Colorado, 2009.

[3] P. G. Willoughby, K. L. Baker, R. W. Hermsen, "Photographic Study of Solid Propellants Burning in an Acceleration Field," in Thirteenth Symposium on combustion, The combustion institute, Pittsburgh, pp. 1033-1043, 1971.

[4] G. P. Sutton, O. Biblarz, Rocket Propulsion Elements. New York, John Wiley, 2001. 